\title{
On the origin and the spreading of the shallow Mediterranean water core in the Iberian Basin
}

\author{
Hans-HaRald HinrichSen* and Monika Rhein* \\ (Received 3 September 1992; in revised form 12 May 1993; accepted 25 May 1993)
}

\begin{abstract}
The origin and the spreading of the shallow Mediterranean water core (Ms) in the Iberian basin is discussed with a quasi-synoptic hydrographic data set enhanced by chlorofluoromethane (CFM) measurements. Its characteristic density level is found to be $\alpha_{\mathrm{t}}=27.4$. Characterized by high temperature and CFM values, Ms enters the Iberian basin in the region of Cape St Vincent between depths of 500-750 dbar. A heat anomaly of $>11.8 \times 10^{9} \mathrm{~J} \mathrm{~m}^{-2}$ is chosen as the boundary between the presence of Ms and the background field. The core is found in a tongue-like shape as well as in separate isolated eddies of both cyclonic and anticyclonic circulation. Using the optimum multiparameter analysis (TOMCZAK and LARGE, 1989, Journal of Geophysical Research, 94, 16141-16149), the North Atlantic Central Water (NACW), which mixes with the Mediterranean outflow to form $\mathrm{Ms}$, turned out to be in the mean $1^{\circ} \mathrm{C}$ warmer and 0.11 saltier than in regions with minor Mediterranean influence. This points to the Gulf of Cadiz as the origin of Ms, where the Mediterranean outflow is in contact with NACW of the appropriate characteristic.
\end{abstract}

\section{INTRODUCTION}

THE mid depths of the Eastern North Atlantic Ocean are the most saline of the major oceanic regimes (WÜST and DEFANT, 1936). This characteristic is related to the outflow of the Mediterranean Water (MW) released through the Straits of Gibraltar. In the Gulf of Cadiz, the outflow, forming an undercurrent, splits into two major branches, mainly guided by the topography: a warmer, less saline upper core around $800 \mathrm{~m}(\mathrm{Mu})$ and a colder, more saline lower one (Ml) around $1200 \mathrm{~m}$ (ZENK, 1970; AMBAR and Howe, 1979; RHEIN and HinRICHSEN, 1993). This structure can be traced into the open ocean (HowE and TAIT, 1972; SIEDLER and ZeNK, 1973). The hydrographic and tracer signal of the MWoutflow through the Straits of Gibraltar is considerably altered in the Gulf of Cadiz, and entrainment of Atlantic water from shallow horizons affects the upper core, $\mathrm{Mu}$, more than Ml (RHeIN and HinRICHSEN, 1993). Moreover, $F 11 / F 12$ ratio of the outflow is equal to that of the ambient Atlantic water in the Gulf, so that besides its potential as a mixing parameter, the $F 11$ and $F 12$ distributions carry no "age" information, which can be obtained otherwise under certain circumstances.

In addition to the double maxima structure of $\mathrm{MW}$, a shallow core (Ms) has been observed in the Gulf of Cadiz and off the southern half of the western coast of Portugal (Zenk, 1975; Ambar and Howe, 1979; Ambar, 1983). This third core was identified at density levels of $\sigma_{\mathrm{t}}=27.45$ in the vicinity of the Straits of Gibraltar and around $\sigma_{\mathrm{t}}=27.3$

\footnotetext{
${ }^{*}$ Institut für Meereskunde an der Universität Kiel, Kiel, Germany.
} 
farther west; it is located between 400 and $700 \mathrm{~m}$. AMBAR (1983) described the evidence of the third, shallower core using CTD, STD and bottle data from cruises of different years. The core appears on a virtual path from the region in the vicinity of the Straits of Gibraltar to around $38^{\circ} 30^{\prime} \mathrm{N}$ in coastal areas off Portugal. The origin of this core was suggested to be similar to the well established two main cores originating as a subdivision of the upper core caused by topographic effects in the Gulf of Cadiz and around Cape St Vincent (AMBar and Howe, 1979). GRüNDLINGH (1981) reported a solitary event in the Gulf of Cadiz with an increase in temperature of $1^{\circ} \mathrm{C}$ for the upper layer of the Mediterranean water level. It coincided with a thickening of the outflow and an increase in volume transport. The origin of this event was traced back into the Straits of Gibraltar, corresponding to anomalous high cross channel water level differences.

Although the third core has been recognized in the past several times, the classical picture of the MW outflow suggests that its existence is quite episodic. The availability of a quasi-synoptic hydrographic data set extended by additional chlorofluoromethane (CFM, compounds $F 11$ and $F 12$ ) measurements allows the description of its mesoscale property fields within the Iberian Basin. In this paper we discuss the distribution of $T, S$, and $F 11$ in the density range of Ms as well as the dynamic circulation. Furthermore, the optimum multiparameter analysis (ToMCZAK and LARGE, 1989; HinRICHSEN and TOMCZAK, 1993) will yield the actual temperature and salinity values of NACW mixed with the MW, defined from observations performed in the Western Alboran Sea and in the Gulf of Cadiz. After presenting the appearance of the third core in the Iberian basin by typical profiles and mean distributions in temperature and salinity and the CFMs, we will outline the horizontal structure of temperature as well as the integrated vertical heat content and the dynamic height field. Finally, the results of the water mass distribution analysis performed by the optimum multi-parameter analysis (OMP) are discussed.

\section{THE DATA}

The observations on which the study is based were obtained on board FS Poseidon during early spring of 1990 . The majority were executed in the near-shelf area off Portugal, reaching from $35^{\circ}$ to $40^{\circ} \mathrm{N}$ and from $9^{\circ} 30^{\prime}$ to $11^{\circ} \mathrm{W}$, although the northern part was more extended, to around $14^{\circ} \mathrm{W}$ (Fig. 1). From 19 March to 3 April, 61 CTD casts were performed, mostly down to depths of around $3000 \mathrm{dbar}$. For 29 of them, CFM measurements are available, additional observation parameters useful for application of the OMP, with 15 stations where the vertical coverage of the CFM values was dense enough to be used in the purpose of this paper. The CFM analysis procedures and the temperature and salinity acquisitions are described in RHEIN and HINRICHSEN (1993). The CFM reproducibilities amount to $\pm 0.015 \mathrm{pmol} \mathrm{kg}^{-1}$ or $\pm 1.2 \%$, whichever is greater.

\section{OBSERVATIONS AND RESULTS}

\section{(a) Typical $\mathrm{T} / \mathrm{S}$ diagrams}

Figure 2 shows a typical appearance of the MW tongue in the Iberian Basin during the observation period. The triple maxima structure of St.406 (Fig. $2 \mathrm{a}$ ) in the $T / S$ domain is mainly attributable to water originating in the Mediterranean Sea. Their extreme values in temperature and salinity correspond to $\sigma_{\mathrm{t}}$-levels of $27.4,27.6$ and 27.8 . The core at the 


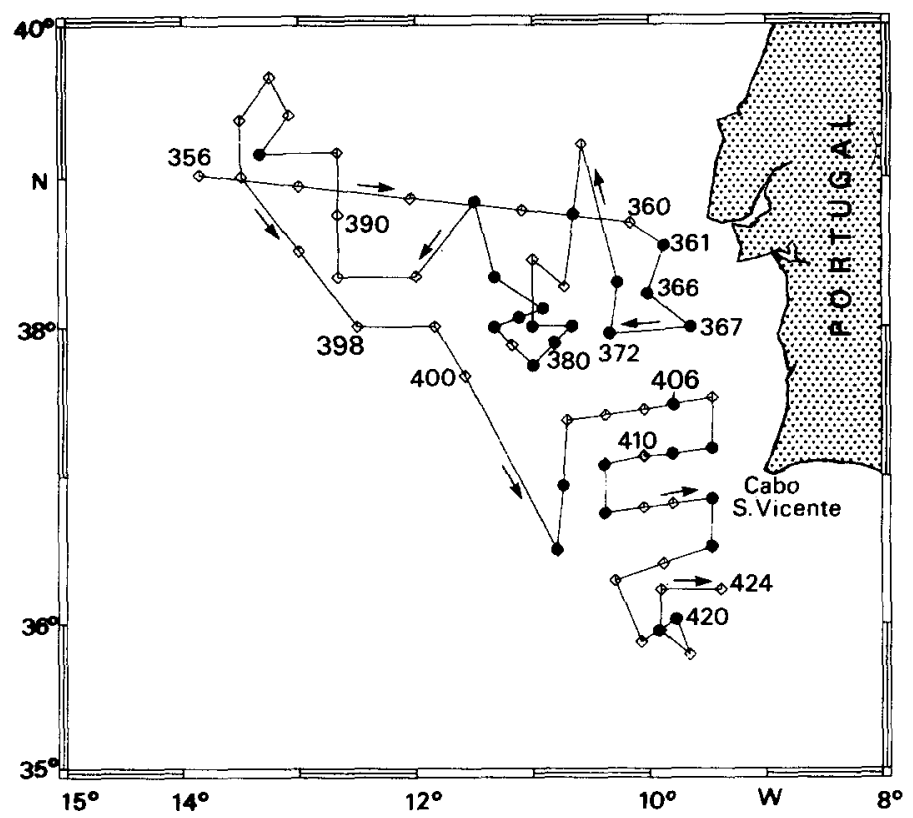

Fig. 1. Cruise track Poseidon 172, March/April 1990 showing CTD stations. Black dots represent stations with evidence of the shallower core.

shallowest level is referred to as the "shallower" one, albeit slightly denser than observed by AMBAR (1993) in the Iberian Basin and warmer and fresher than any other maximum. Station 406 was located within the MW undercurrent $\left(37^{\circ} 30^{\prime} \mathrm{N}, 9^{\circ} 48^{\prime} \mathrm{W}\right)$ exhibiting smallscale perturbations probably due to intrusions of colder and fresher water masses and subsequent mixing. At St.422 (located in a Meddy observed at $35^{\circ} 57^{\prime} \mathrm{N}, 9^{\circ} 55^{\prime} \mathrm{W}$ ) the smooth shape of the curvature in the $T / S$-domain (Fig. 2b) suggests that this Meddy was still less influenced by surrounding water masses, conserving its generation state during the movement away from the assumed source at $7^{\circ} \mathrm{W}$ (RHEIn and HinRichsen, 1993). Again, $T / S$ characteristics yield the typical triple maximum distribution, although the signal of $\mathrm{Ms}$ is less pronounced. Maximum values are $13.8^{\circ} \mathrm{C}$ in temperature and 36.5 in salinity, which are remarkably high compared to the characteristics outside of this Meddy. The CFM profiles in the undercurrent (St.409) and in the Meddy (St.422) are depicted in Fig. 2c and compared to a profile with minor influence of MW (St.398); apparently, the presence of MW and, therefore, also of Ms increase the CFM concentrations and help separate the various water masses in the Iberian basin. CFMs were additionally used in the OMP.

\section{(b) Mean distributions}

On average the depth range between 500 and 750 dbar represents the upper and lower boundaries for the shallower core as observed during our hydrographic survey. Vertical profiles of $T$ of this depth range (Fig. 3), display both horizontal averages for all stations as well as for those stations, where Ms is evident. The distinguishing features of Ms are indicated first by their differences in $T$ and $S$ from the mean. Maximum differences for temperature were obtained between 625 and $700 \mathrm{dbar}\left(0.8^{\circ} \mathrm{C}\right)$, whereas differences for 
(a)

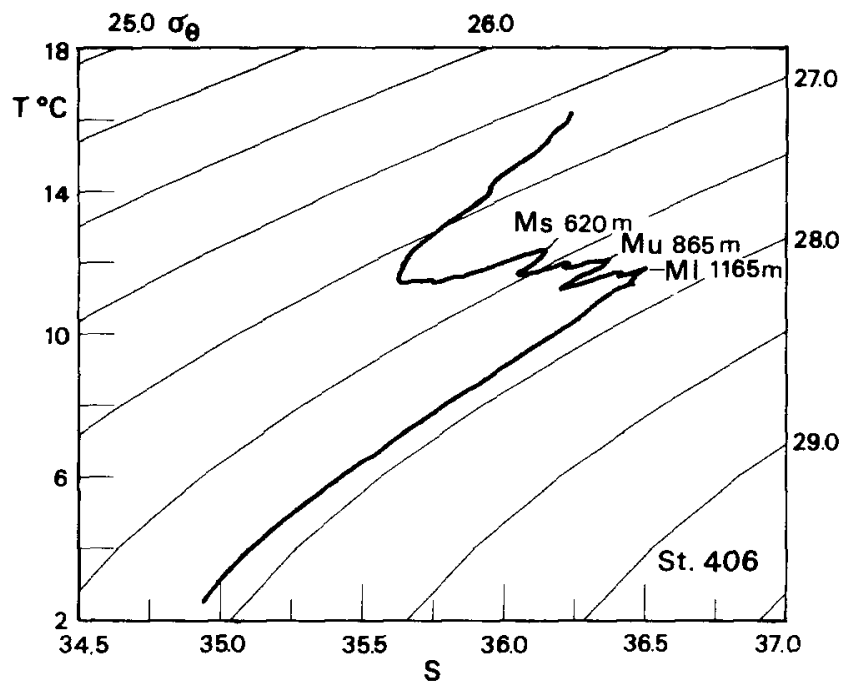

(b)

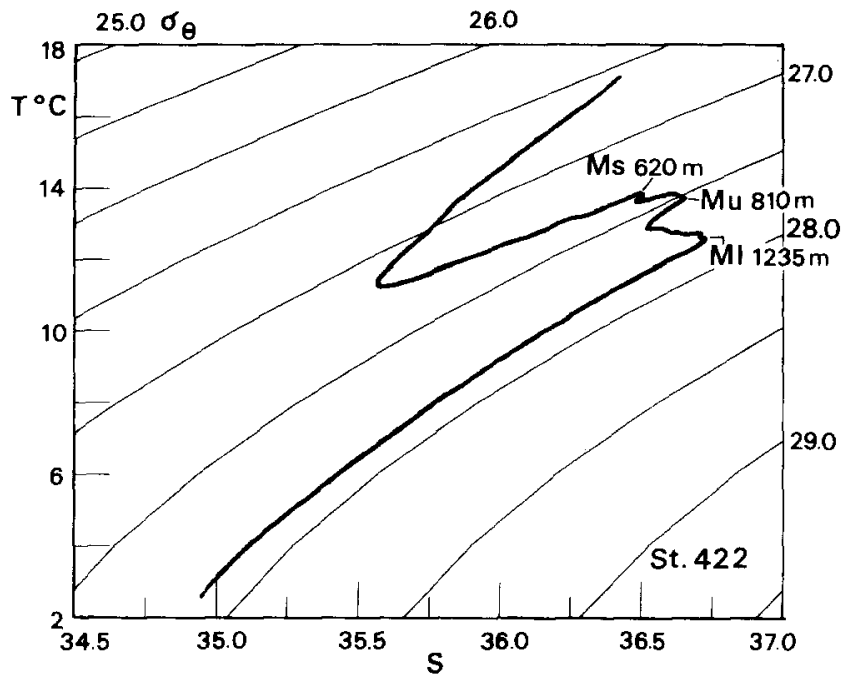

(c)

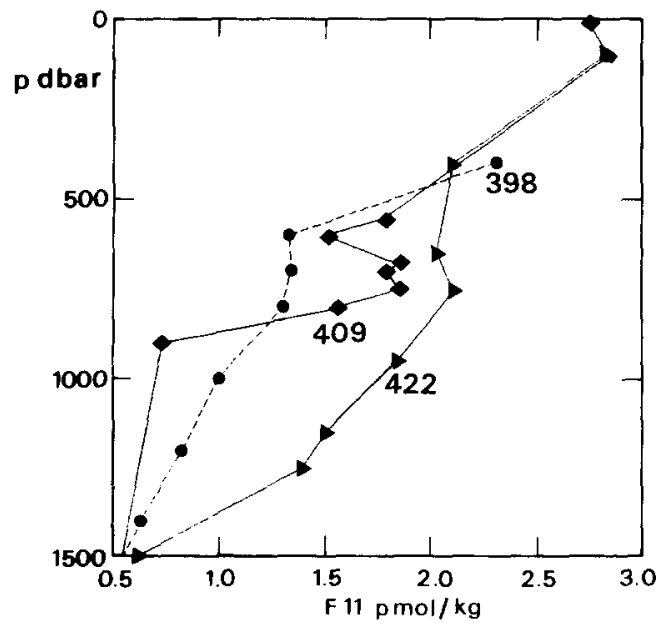


salinity (0.3) were limited to a smaller depth range (not shown). Figure 3 shows the separation of Ms from the relatively colder and fresher $\mathrm{Mu}$, which is located below Ms. Decreasing differences deeper than $700 \mathrm{dbar}$ might demonstrate that a shallow intrusion of warm and saline water of Mediterranean origin could be identified, distinct from the well established two main cores. Water of high temperature and salinity results in anomalous high heat and salt contents below the deepest layer of NACW, which is not affected by MW. Modifications of property contents, although of episodical character, could, however, have consequences for the circulation and mixing processes.

\section{(c) Horizontal structure}

Horizontal maps are constructed by an objective analysis method (HILLER and KäsE, 1983) using an isotropic correlation scale of $50 \mathrm{~km}$ due to a mean minimum horizontal data distance of around $29 \mathrm{~km}$. Application of this method generally results in smoothing of the data; therefore variability in the estimated field is reduced.

The characteristic density level $\sigma_{\mathrm{t}}$ for the shallower core was found to be 27.4. Extreme temperature values at this level range from 10.8 to $13.1^{\circ} \mathrm{C}$ (Fig. 4). The geographical distribution emphasizes the role of the MW spreading into the Iberian Basin. Obviously in the vicinity of Cape St Vincent, relatively high temperatures occur, building a southeastnorthwestward orientated tongue-like shape. Further continuation of this tongue seems to be diminished towards the northwest by an isolated feature of colder water $\left(<11.4^{\circ} \mathrm{C}\right)$ at $37^{\circ} 30^{\prime} \mathrm{N}, 10^{\circ} 30^{\prime} \mathrm{W}$, as well as inshore of the tongue, where lower temperatures were found. Additionally, some more isolated structures of opposite character were resolved, for example, at $36^{\circ} \mathrm{N}, 10^{\circ} \mathrm{W}$ and $39^{\circ} \mathrm{N}, 13^{\circ} 30^{\prime} \mathrm{W}$, both coinciding with areas where Meddies are observed. The distribution in this layer yields separate structures with estimated horizontal scales of $c a 100 \mathrm{~km}$, possibly generated by baroclinic instability of a northward mid depth jet of MW (BECKMANN and KÄSE, 1989). Moreover, intrusions of colder and fresher water found in the southern part of our observation area $\left(10.2^{\circ} \mathrm{C}\right.$ at $\left.36^{\circ} 30^{\prime} \mathrm{N}, 10^{\circ} \mathrm{W}\right)$ suggest that the general southward movement of these water masses could be enhanced by this baroclinic instability. The vertically integrated total heat content between 500 and 750 dbar very well reflects the temperature distribution of this layer in the Iberian Basin (Fig. 5). Estimating the additional heat content for this layer, we refer to Fig. 3, where the horizontal averages of temperatures were shown (broken line). Vertical integration of this mean profile amounts to $11.9 \times 10^{9} \mathrm{~J} \mathrm{~m}^{-2}$. Taking into consideration that our data fields were somewhat smoothed by application of the objective analysis method, we choose areas containing more than $11.8 \times 10^{9} \mathrm{~J} \mathrm{~m}^{-2}$ heat as representative for the existence of the shallower core. Its appearance extends to $39^{\circ} \mathrm{N}, 12^{\circ} \mathrm{W}$, although an isolated structure $\left(>11.8 \times 10^{9} \mathrm{~J} \mathrm{~m}^{-2}\right.$ ) occurs at $39^{\circ} \mathrm{N}, 13^{\circ} 30^{\prime} \mathrm{W}$. Starting from the $11.8 \times 10^{9} \mathrm{~J} \mathrm{~m}^{-2}$ contour line, a positive heat content anomaly of about $0.9 \times 10^{19} \mathrm{~J}$ is obtained by horizontal integration. This is about $25 \%$ of the heat anomaly of a Meddy observed in the Canary Basin (ARMI et al., 1989).

While the distribution of properties of Ms is relevant for water mass tracing, the dynamic

Fig. 2. Typical property distributions in the Iberian Basin: (a) $T / S$ diagram at St. 406 located within the MW undercurrent; (b) $T / S$ diagram at St. 422 located to a Meddy; (c) F11 profiles of St. 398 (minor MW influence), St. 409 (MW undercurrent), and St. 422 (Meddy C). 


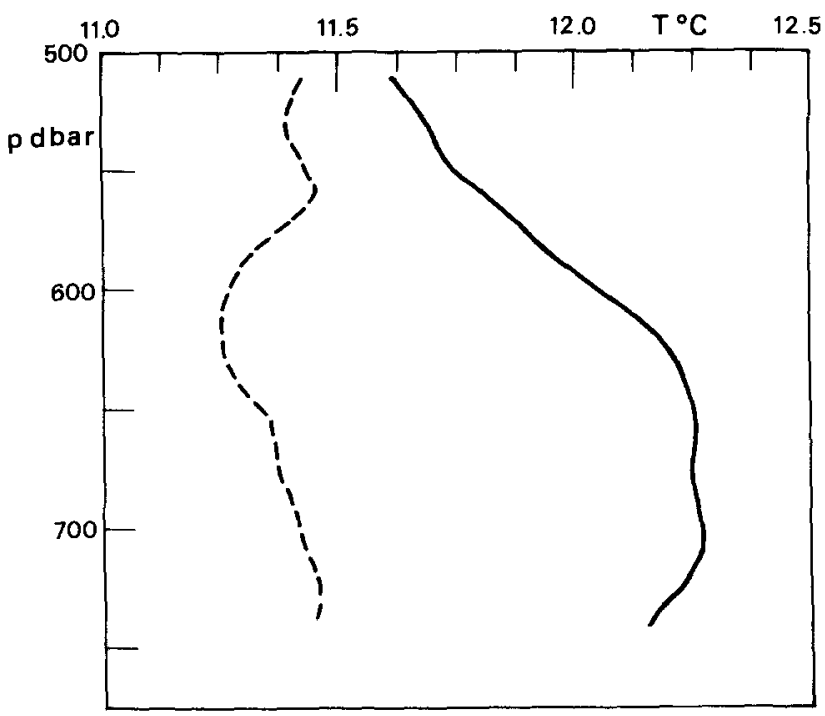

Fig. 3. Mean temperature profile between 500 and $750 \mathrm{dbar}$. Broken line refers to the arithmetic mean of all stations, whereas the full line represents only the mean of those stations, which are highly influenced by $\mathrm{MW}$.

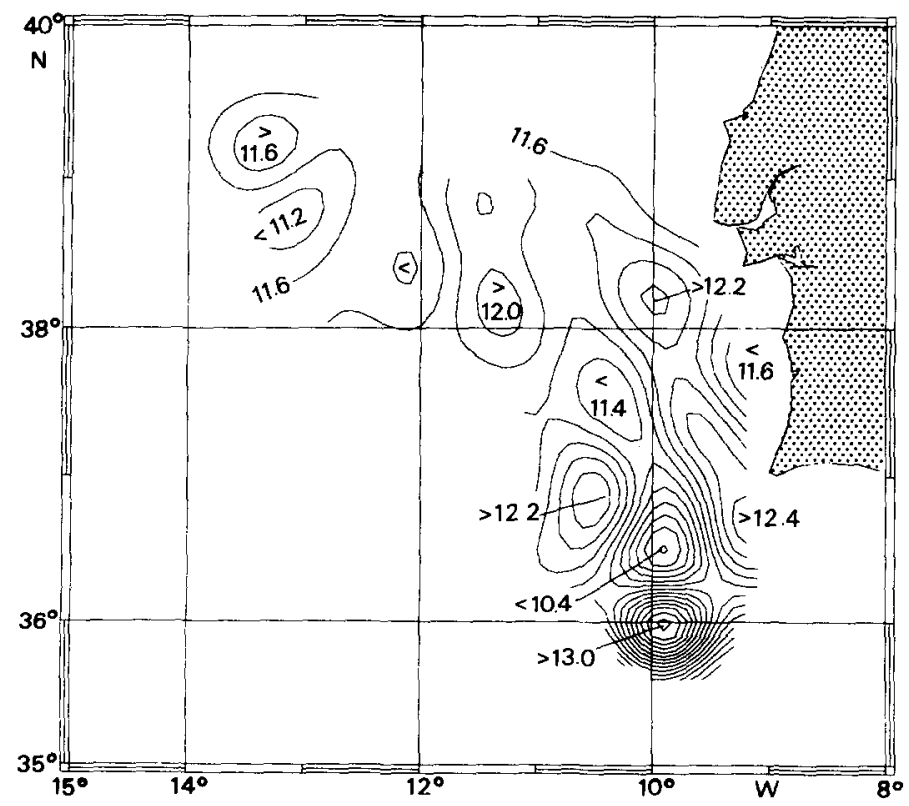

Fig. 4. Temperature at the shallower core level $\left(\sigma_{\mathrm{t}}=27.4 \mathrm{~kg} \mathrm{~m}^{-3}\right)$. 


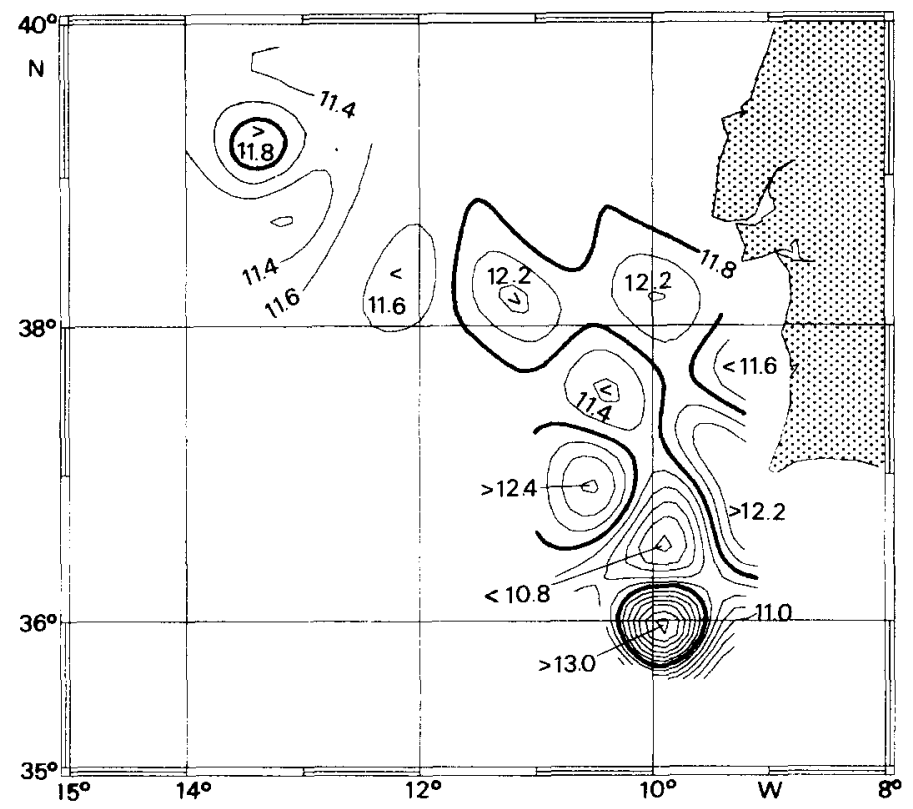

Fig. 5. Vertically integrated total heat content $\left[\mathrm{J} \mathrm{m}^{-2} \times 10^{9}\right]$ between 500 and 750 dbar.

height field is more relevant for the dynamical structures of the circulation. The circulation in the shallower core layer resulting from the geostrophic mass transport stream function field of $500 / 750$ dbar with respect to a reasonable level of no motion at 2000 dbar is shown in Fig. 6. The dynamical situation does not support the picture of a tongue-like spreading of the MW into the Iberian Basin. On the contrary, the mesoscale eddy field reveals separated anticyclonic and cyclonic features with mass transports between 0.8 and $2.2 \mathrm{~Sv}$. The marked features $\mathrm{A}, \mathrm{B}$ and $\mathrm{C}$ are of anticyclonic rotation, all of them corresponding to typical Meddy structures (KäsE et al., 1989), described below. A similar spreading pattern is observed for Mu (HinRICHSEN et al., 1993). The circulation pattern for D is of quite different character. Whereas the property distributions (Figs 4 and 5) yield anomalously high contents of warm and saline water between 500 and $750 \mathrm{dbar}$, for which we might expect anticyclonic circulation, the relations here are reversed. A cell of strong cyclonic rotation of about $2.2 \mathrm{~Sv}$ appears, resulting from the influence of the dynamical structures of the deeper layers, which are characterized by the absence of the two well established main cores and the lateral influence of water from higher latitudes. This suggests a similar explanation of the dynamical circulation to a so-called "Anti Meddy", observed in the North Atlantic around $47^{\circ} \mathrm{N}, 20^{\circ} \mathrm{W}$ (Schauer, 1989).

\section{MIXTURE OF NACW IN MS}

Water masses are physical properties of finite volume; mathematically they can be described by a linear functional relationship between their characteristics (e.g. temperature, salinity and CFMs). For our purpose we attempt to clarify the origin of Ms, described as a mixture between the original outflowing MW released through the Straits of Gibraltar and the central water masses of the northern Atlantic, using the OMP with $T, S$ and $F 11$ as 


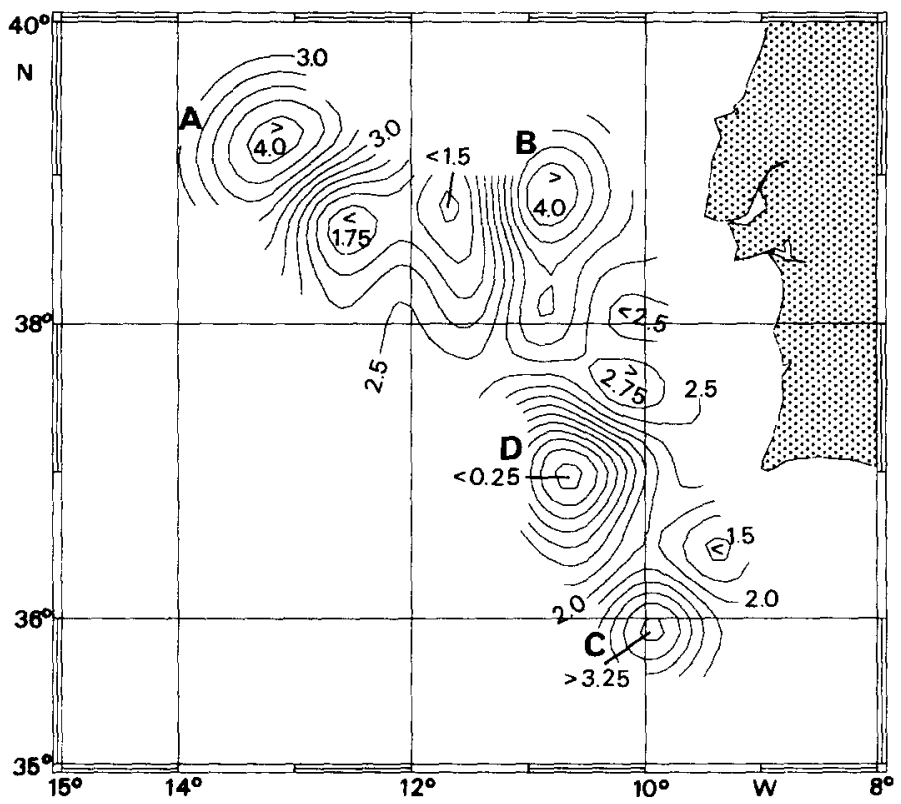

Fig. 6. Geostrophic mass transport (Sv) between 500 and $750 \mathrm{dbar}$, level of no motion at 2000 dbar.

Table 1. Water type definition. [The characteristics of the water masses are obtained by linear regression of our data set of the Iberian Basin and the Gulf of Cadiz (RHEIN and HINRICHSEN (1993)]

\begin{tabular}{|c|c|c|c|c|}
\hline Parameter & $\mathrm{NACWu}$ & $\mathrm{NACWI}$ & MW & NADW \\
\hline Temperature $\left({ }^{\circ} \mathrm{C}\right)$ & 18.00 & 10.00 & 13.35 & 4.00 \\
\hline Salinity & 36.497 & 35.400 & 38.400 & 35.130 \\
\hline$F 11($ pmol kg-1) & 3.05 & 1.19 & 1.40 & 0.10 \\
\hline
\end{tabular}

parameters. Note that the characteristics of central water masses are rather well described by a straight line between two property combinations. Linear regression of our observed data results in the water type definition in Table 1. The applied method solves the set of mixing equations through minimization of the least squares residuals (for details see TOMCZAK and LARGE, 1989).

The analysis presented here is based on observations of 46 stations, where the existence of the shallower core is represented by temperature and salinity pairs only. Furthermore, 15 stations with additional chlorofluoromethane observations were available. Figure 7 shows the fraction of $\mathrm{MW}$ at $\sigma_{\mathrm{t}}=27.4$. The analysis was able to reproduce all observations with the defined endmembers of MW and NACW (Table 1), although weak variability is present. The fraction of the Mediterranean endmember varies from 0.08 to 0.23 on $\sigma_{\mathrm{t}}=$ 27.4 (Fig. 7) with the maximum found in the center of Meddy $C$. The contribution of MW to the northwestward oriented tongue does not exceed 0.17 , whereas the fraction $(0.23)$ 


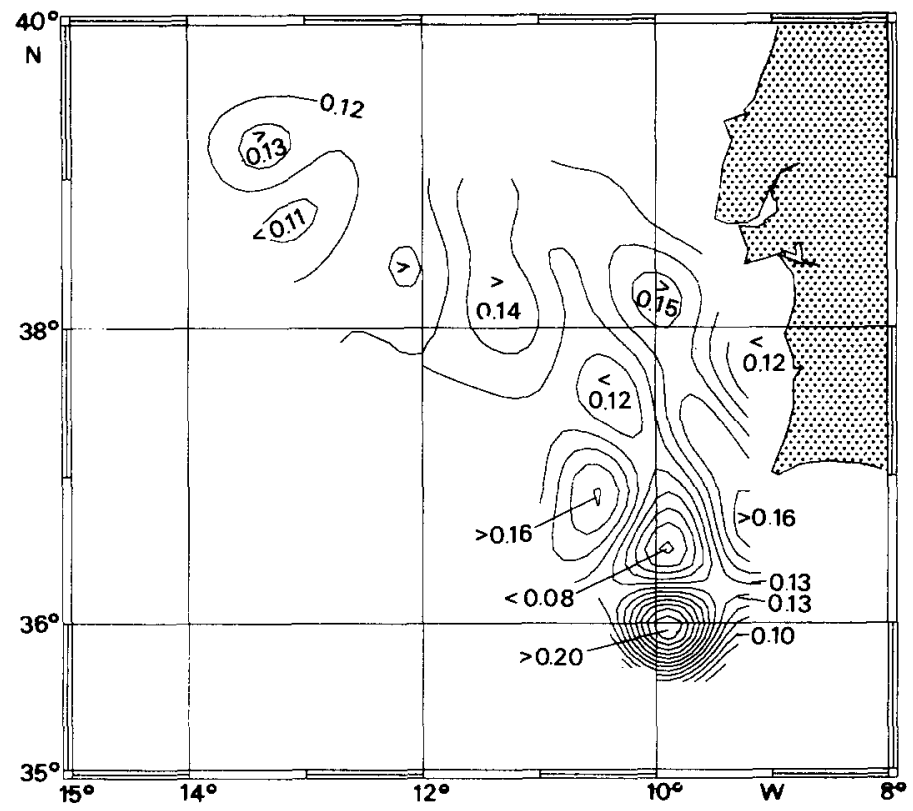

Fig. 7. Fraction of Mediterranean Water at $\sigma_{\mathrm{t}}=27.4 \mathrm{~kg} \mathrm{~m}^{-3}$ (for water mass definition see Table 1).

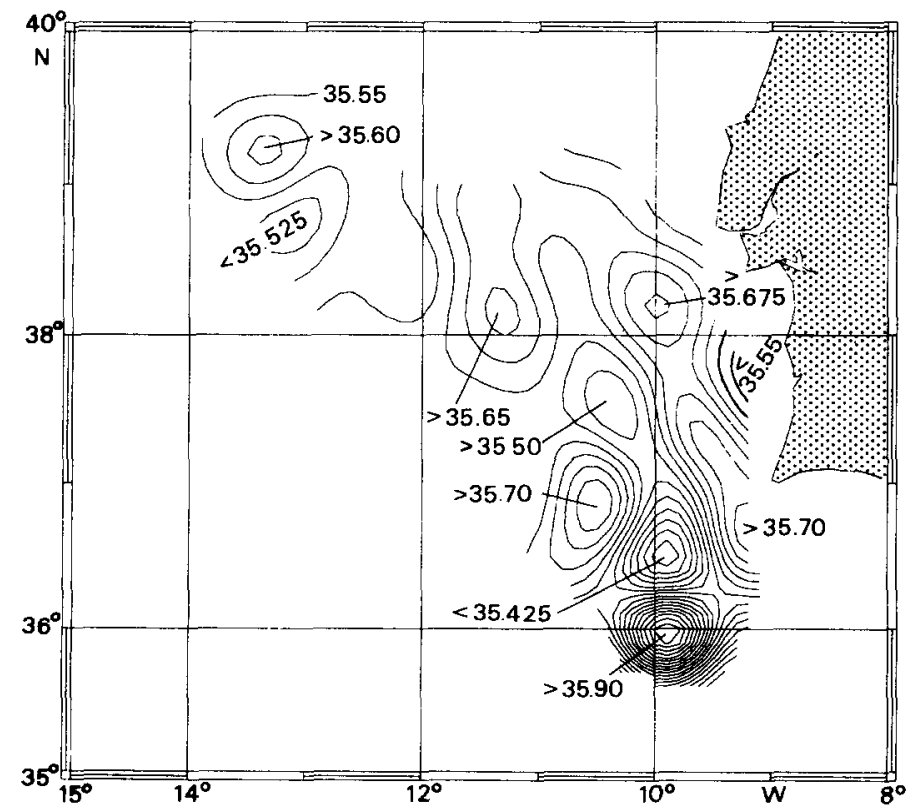

Fig. 8. Salinity of admixed North Atlantic Central Water at $\sigma_{\mathrm{t}}=27.4 \mathrm{~kg} \mathrm{~m}^{-3}$. 
for Meddy C, and its high $F 11$ concentrations supports the statement that its generation was around $7^{\circ} \mathrm{W}$ in the Gulf of Cadiz (RHein and Hinrichsen, 1993). The NACW, which mixes with the MW at the $\sigma_{\mathrm{t}}=27.4$ layer, has temperatures of $11.9 \pm 0.5^{\circ} \mathrm{C}$ and salinities of $35.66 \pm 0.07$, where the shallow core is present (heat content $>11.8 \times 10^{9} \mathrm{~J} \mathrm{~m}^{2}$ ) (Fig. 8). In regions with minor influence of $\mathrm{Ms}$, the admixed $\mathrm{NACW}$ is cooler $\left(11.09 \pm 0.4^{\circ} \mathrm{C}\right)$ and fresher $(35.55 \pm 0.05)$; these values match closely to the intermediate salinity minima values of NACW. Figure 8 represents the salinity of admixed water types of NACW at $\sigma_{\mathrm{t}}=$ 27.4. The presence of Ms, however, points to mixing with NACW originating in the mean from about $350 \mathrm{~m}$ depth, and in the area of Meddy C, even NACW from $200 \mathrm{~m}$ depth with a salinity of 35.92 and a temperature of $13.8^{\circ} \mathrm{C}$ is found to be the mixing endmember. The major part of Ms represents the mixing with water types of relatively high temperatures and salinities, which mainly occur in the Gulf of Cadiz, where the Mediterranean outflow is in contact with NACW of that character. The higher temperatures and salinities of NACW admixed in the presence of Ms indicates that a major part of the mixing occurs in the Gulf of Cadiz, where the Mediterranean outflow is in contact with NACW of that characteristic. The cold and fresh water intrusion at $36^{\circ} 30^{\prime} \mathrm{N}, 10^{\circ} \mathrm{W}$ was correlated to mixtures of NACW, below the typical intermediate salinity minimum layer of the Iberian Basin.

Acknowledgements-We are grateful to the officers and crew of FS Poseidon for assistance and support during cruise 172 . Especially we would like to thank A. Eisele for carefully preparing the figures and T. Elbrächter who performed many of the CFM analyses. The work was supported by the Deutsche Forschungsgemeinschaft (SFB 133 "Warmwassersphäre des Atlantiks").

\section{REFERENCES}

Ambar I. (1983) A shallow core of Mediterranean water off western Portugal. Deep-Sea Research, 30, 677-680.

Ambar I. and M. R. Howe (1979) Observation of the Mediterranean outflow, I. Mixing in the Mediterranean outflow. Deep-Sea Research, 26, 535-554.

Armi L., D. Hebert, N. Oakey, J. Price, P. L. Richardson, T. Tossby and B. Ruddick (1989) Two years in the life of a Mediterranean salt lens. Journal of Physical Oceanography, 19, 354-370.

BEckMANN A. and R. H. KÄSE (1989) Numerical simulation of the movement of a Mediterranean water lens. Geophysical Research Letters, 16, 65-68.

GründLINGH M. L. (1981) On the observation of a solitary event in the Mediterranean outflow west of Gibraltar. "Meteor" Forsch.-Ergebn., ser A, 23, 15-46.

HILlER W. and R. H. KÄSE (1983) Objective analysis of hydrographic data sets from mesoscale surveys. Ber. Inst. Meereskd. Univ. Kiel, 116, 78 pp.

HinRICHSEN H.-H. and M. ToMCZAK (1993) Optimum multiparameter analysis of the water mass structure in the western North Atlantic Ocean. Journal of Geophysical Research, 98, 10155-10169.

Hinrichsen H.-H., M. Rhein, R. H. KÄSE and W. Zenk (1993) The Mediterranean water tongue and its chlorofluoromethanes signal in the Iberian basin in early summer 1989. Journal of Geophysical Research, 98, 8405-8412.

HowE M. R. and R. I. TAIT (1972) The role of temperature inversions in the mixing processes of the deep ocean. Deep-Sea Research, 19, 781-791.

Käse R. H., A. Beckmann and H.-H. Hinrichsen (1989) Observational evidence of salt lens formation in the Iberian Basin. Journal of Geophysical Research, 94, 4905-4912.

RHEIN M. and H.-H. HinRICHSEN (1993) Modification of Mediterranean Water in the Gulf of Cadiz, studies with hydrographic, nutrient and chlorofluoromethane data. Deep-Sea Research, 40, 267-291.

Schauer U. (1989) A deep saline cyclonic eddy in the West European Basin. Deep-Sea Research, 36, $1549-1565$.

Siedler G. and W. ZeNK (1973) Variability of the thermocline staircase. Nature, 244(131), 11-12.

TomczaK M. and D. G. B. LARGe (1989) Optimum multiparameter analysis of mixing in the thermocline of the Eastern Indian Ocean. Journal of Geophysical Research, 94, 16141-16149. 
Wüst G. and A. Defant (1936) Atlas zur Schichtung und Zirkulation des Atlantischen Ozeans, Schnitte und Karten von Temperatur, Salzgehalt und Dichte. Wiss. Ergeb. Dtsch. Aff. Exped. Vermessungs. Forschungsschiff Meteor 1925-1927, Vol. 6, atlas, 103 plates.

ZENK W. (1970) On temperature and salinity structure of the Mediterranean water in the N.E. Atlantic. DeepSea Research, 17, 627-632.

ZENK W. (1975) On the origin of the intermediate double-maxima in $T / S$ profiles in the North Atlantic. "Meteor" Forsch.-Ergebn., ser. A, 16, 35-43. 